time and the sun was clearly reflected on a distant wet mud flat, no doubt forming an extension of the northward sloping beach, so as to give an image below the level of the observer's eye and to the left of the sun, that is to say, lying in a direction somewhat farther round towards the south. Mr. Evans attributes the third bow to this additional source of light. It appeared as a short are with colours arranged in the same order as those in the primary bow, with an apparent centre of curvature above the horizon and north of the centre of curvature of the two ordinary bows. He estimated that about two-thirds of a complete circle would have been above the horizon had the arc continued far enough, while the two normal bows would have shown to only half that extent above the horizon. The explanation offered seems to accord well with the observed effect.

\section{Distributive Enterprises in the United States}

IN the United States decennial census of population for 1930 , there was included, for the first time in any country, a special census of distributive enterprises and activities. In order to bring this important innovation to the attention of business men, traders and others, a report has been prepared for the International Distribution Commission by the International Management Institute (2, Boulevard du Théatre, Geneva, pp. 72 ; 2 Swiss francs). This report points out that the American experiment in the statistical study of a hitherto neglected aspect of economic activity is likely to prove extremely valuable to other countries. The distribution census provides a complete guide to the position in the United States in 1930 with regard to distributive enterprises throughout the country, including particulars of their size, turnover, expenditure, number of employees, type of organisation and similar facts. The census of distribution is complementary to a census of production since it is an attempt to establish the exact statistical facts as to the various enterprises engaged in distributive as opposed to productive activities. The material provided should be of particular value to small retailers since they will obtain facts and information which larger concerns have in the past gathered for themselves at considerable expense. The census provides a unique contribution towards the study of an important aspect of economic organisation. Greater distributive efficiency would increase the power of the market to absorb goods and services, whereas at present, production is limited to the capacity of ill-organised markets.

\footnotetext{
Aiming at $\mathrm{I}, 000$ kilovolts for the Transmission of Power AN account by Mr. T. Rich of a recent High Tension Congress at Paris is given in the Electrician beginning on July 28. The problems of the use of direct current for power transmission and the many uses of thermionic converters were discussed in several papers. M. Sitnikov, of Leningrad, described a system of thermionic converters with cold electrodes and magnetic control which possesses many advantages for the transmission of power by direct current.
}

Experiments prove that, for a discharge in gas, the limit of the current which can be passed by the tube is determined by the limiting value of the power which can be given out by the two cold electrodes at a sufficiently low temperature so that their surfaces suffer no deterioration. The gaseous column will carry practically any current, provided the energy can be taken from the electrodes. A tube tested up to 70 kilovolts operated quite satisfactorily up to 30 kilovolts. A plan is under consideration in Russia for the transport of a million kilowatts at a pressure of the order of 600 kilovolts. The necessary researches in connexion with the converter tubes are being carried out in Leningrad. Mr. E. S. Henriksen, of the Norwegian Nitrogen Co., described the development of valves with grid control for very high tensions. He stated that if 400 kilovolts is the highest voltage practical with three phase current, then with direct current 725 kilovolts is possible with overhead transmission and 1,000 kilovolts with underground cables. Various schemes were discussed relating to a project for transporting power from Norway to the north of France. It will be remembered that the voltage of the English 'grid' is 132 kilovolts.

\section{An Industrial Jubilee in Sweden}

In the Asea Journal (Allmanna Svenska Elektriska) for April there is an interesting account of the jubilee of the Asea Electric Co., which was founded fifty years ago. In 1883 , it employed seven workmen and the total horse power of all the machines manufactured was 62. For the ten years before the War, the development of hydro-electric supply systems in Sweden created a great demand for electric machinery. During the War, thanks to the neutrality of Sweden, the business rapidly increased. The scarcity of petrol also gave a great impulse to the use of electrical energy and networks of wires were erected over various parts of the country. For the last ten years new forms of rationalisation have been introduced into the various branches of the business, and last year it employed 10,000 workmen and the horse power of the machines manufactured reached a total of one and a half million. The celebrations were initiated by a special performance at the Royal Opera House in Stockholm to which all its employees were invited. In Sweden it is the custom for the Royal Patriotic Society to present long-service medals to persons industrially employed as a token of recognition for faithful and loyal service. Two hundred and forty-four of the company's workmen and engineers were presented with the 30 years' medal. At the conclusion of the ceremonies the directors gave donations amounting to $£ 40,000$.

\section{Eighteenth Century Map of Hampshire}

WE have received from the Hampshire Field Club and Archæological Society a copy of the reproduction, on a slightly reduced scale, of the map of Hampshire by Isaac Taylor, 1759, which has recently been published by the Society (Winchester : price to nonmembers $6 s$. net). The scale of the original map is one inch to the mile, the reproduction being threequarters of an inch to the mile. The map is a beautiful 